Editorial

\title{
Hearing Loss, Tinnitus, and Dizziness and their Relation with Covid-19: what is the Current Evidence?
}

\author{
Ricardo Ferreira Bento ${ }^{10}$ Tatiane Vacaro Campos ${ }^{10}$ \\ ${ }^{1}$ Department of Ophthalmology and Otorhinolaryngology, Hospital \\ das Clínicas, Faculty of Medicine, University of São Paulo, São Paulo, \\ Brazil
}

Int Arch Otorhinolaryngol 2022;26(1):e1-e2.

Since the emergence of coronavirus disease 19 (COVID-19) caused by severe acute respiratory syndrome coronavirus 2 (SARS-COV-2), the world has been battling a severe pandemic. What initially seemed to be only a respiratory tract infection, soon proved to be a systemic pathology, ranging from asymptomatic to lethal, whose mechanisms of action involves both inflammatory and thromboembolic processes. The otorhinolaryngological symptoms most commonly observed for this disease are odynophagia and runny nose, but changes in smell and taste are commonly associated with COVID-19, suggesting that the virus may have also involve sensory or neural structures. ${ }^{1}$

In the field of otology, symptoms such as hearing loss, tinnitus and dizziness have also been related to COVID-19, a fact that had never been described in association with infections by other coronaviruses, such as Severe Acute Respiratory Syndrome (SARS) and Middle East Respiratory Syndrome (MERS). Since the start of the pandemic, reports of sudden deafness and acute vestibular symptoms in patients infected with SARS-COV-2 have been published. ${ }^{2,3}$ Performance declines in cochlear implant $(\mathrm{CI})$ users have also been described as an initial symptom of COVID-19 infection, as well as altered otoacoustic emissions in infants with intrauterine exposure to the virus. ${ }^{4,5}$

Several studies have been conducted in an attempt to clarify the relation between otologic symptoms and SARSCOV-2 infection; however, the lesser severity of these symptoms, the difficulty in performing objective tests during the acute phase of the disease and data collection in a truly representative sample of the population have interfered with their quality. The real prevalence of hearing loss, tinnitus and dizziness in patients with COVID-19 is therefore unknown. Özçelik Korkmaz et al. ${ }^{6}$ (2021) found a $31.8 \%$ prevalence of dizziness, $11 \%$ of tinnitus, and $5.1 \%$ of hearing loss in 116 inpatients, while Freni et al. ${ }^{7}$ (2020) evaluated 20 outpa- tients and found onset or worsening of pre-existing hearing loss and tinnitus in $40 \%$ and $20 \%$ of cases, respectively. ${ }^{6,7}$

Considering the pathophysiology of the disease, mechanisms that could explain the audio-vestibular symptoms include: direct virus infection causing cochleitis or neuritis of the VIII cranial nerve; cochleo-vestibular damage secondary to cytokine storm; ischemic processes or autoimmune dysfunction, caused by cross-reaction of antibodies or T cells against inner ear antigens. ${ }^{2,3,8}$

SARS-COV-2 virus enters cells by binding to angiotensinconverting enzyme 2 (ACE2) receptors. A recent study conducted at the Massachusetts Institute of Technology (MIT) and Massachusetts Eye and Ear identified that both hair cells and Schwann cells of the inner ear express ACE2 and two more enzymes, furin and transmembrane protease serine 2 , that help the virus fuse into the host cell. These findings indicate that direct SARS-COV-2 infection is associated with audio-vestibular dysfunction in COVID-19. ${ }^{9}$

The development of specific vaccines has allowed a significant reduction in the number of new cases, resulting in a significant decrease in mortality associated with COVID-19. However, as vaccines do not prevent contamination nor completely protect against infection, we should consider a diagnosis of COVID-19 for all patients who present with hearing loss, tinnitus or dizziness without other justifiable causes. Vaccines are essential to control the pandemic, but cases of sudden deafness, tinnitus, vertigo and facial paralysis have been reported after their application. However, there are still no definitive data on the incidence of these symptoms as side effects, as well as whether the prevalence would be higher for vaccines against SARS-COV-2 than for vaccines against another virus. ${ }^{10-13}$ Another reason for warning is the emergence of new strains of the virus that are currently triggering an increase in the number of cases.
Address for correspondence Tatiane Vacaro Campos, MD, 25 Dr. Enéas Carvalho de Aguiar

Avenue, 6163, São Paulo, SP 05403-000, Brazil (e-mail: tatiane. campos@hc.fm.usp.br).
DOI https://doi.org/ 10.1055/s-0042-1742353. ISSN 1809-9777. (c) 2022. Fundação Otorrinolaringologia. All rights reserved.

This is an open access article published by Thieme under the terms of the Creative Commons Attribution-NonDerivative-NonCommercial-License, permitting copying and reproduction so long as the original work is given appropriate credit. Contents may not be used for commercial purposes, or adapted, remixed, transformed or built upon. (https://creativecommons.org/ licenses/by-nc-nd/4.0/)

Thieme Revinter Publicações Ltda., Rua do Matoso 170, Rio de Janeiro, RJ, CEP 20270-135, Brazil 
It is important to highlight that factors other than the primary infection itself can generate otoneurologic symptoms, particularly tinnitus and dizziness. The impact of the pandemic itself, generating stress and anxiety, has been linked to an increase in the perception of tinnitus. ${ }^{14}$ Imbalance and instability are the most frequently encountered forms of dizziness and seem to be related to metabolic and nutritional dysfunctions due to severe illness as well as dysautonomia. $^{15}$

Finally, current knowledge suggests that SARS-COV-2 may be responsible for otologic symptoms. ${ }^{9,16}$ Despite this, we still need concrete answers about the real prevalence of these symptoms in patients affected with COVID-19, as well as the mechanisms involved in this process. A multidisciplinary research group at the Hospital das Clínicas of the Faculty of Medicine of the University of São Paulo (HCFMUSP) is developing a study whose first phase investigated a cohort of more than 800 patients between 06 and 11 months after their hospitalization for COVID-19, evaluating several data related to signs and symptoms of the disease, including hearing loss, tinnitus and dizziness. We hope that this study can contribute to the answers needed to define specific assessment and treatment protocols.

\section{Conflict of Interest}

The authors have no conflict of interest to declare.

\section{References}

1 Brandão Neto D, Fornazieri MA, Dib C, et al. Chemosensory Dysfunction in COVID-19: Prevalences, Recovery Rates, and Clinical Associations on a Large Brazilian Sample. Otolaryngol Head Neck Surg 2021;164(03):512-518. Doi: 10.1177/0194599820954825

2 Lang B, Hintze J, Conlon B. Coronavirus disease 2019 and sudden sensorineural hearing loss. J Laryngol Otol 2020 1-3:1-3; Epub ahead of print. Doi: 10.1017/S0022215120002145

3 Degen C, Lenarz T, Willenborg K. Acute Profound Sensorineural Hearing Loss After COVID-19 Pneumonia. Mayo Clin Proc 2020;95 (08):1801-1803. Doi: 10.1016/j.mayocp.2020.05.034

4 Saki N, Karimi M, Bayat A. Cochlear implant failure following COVID 19: Report of two cases. Am J Otolaryngol 2021;42(03): 102910. Doi: 10.1016/j.amjoto.2021.102910
5 Celik T, Simsek A, Koca CF, Aydin S, Yasar S. Evaluation of cochlear functions in infants exposed to SARS-CoV-2 intrauterine. Am J Otolaryngol 2021;42(04):102982. Doi: 10.1016/j.amjoto.2021. 102982

6 Özçelik Korkmaz M, Eğilmez OK, Özçelik MA, Güven M. Otolaryngological manifestations of hospitalised patients with confirmed COVID-19 infection. Eur Arch Otorhinolaryngol 2021; 278(05):1675-1685. Doi: 10.1007/s00405-020-06396-8

7 Freni F, Meduri A, Gazia F, et al. Symptomatology in head and neck district in coronavirus disease (COVID-19): A possible neuroinvasive action of SARS-CoV-2. Am J Otolaryngol 2020;41(05): 102612. Doi: 10.1016/j.amjoto.2020.102612

8 Chandrasekhar SS, Tsai Do BS, Schwartz SR, et al. Clinical Practice Guideline: Sudden Hearing Loss (Update). Otolaryngol Head Neck Surg 2019;161(1_suppl, suppl)S1-S45. Doi: 10.1177/01945 99819859885

9 Jeong M, Ocwieja KE, Han D, et al. Direct SARS-CoV-2 infection of the human inner ear may underlie COVID-19-associated audiovestibular dysfunction. Commun Med 2021;1:44. Doi: 10.1038/ s43856-021-00044-w

10 Formeister EJ, Chien W, Agrawal Y, Carey JP, Stewart CM, Sun DQ Preliminary Analysis of Association Between COVID-19 Vaccination and Sudden Hearing Loss Using US Centers for Disease Control and Prevention Vaccine Adverse Events Reporting System Data. JAMA Otolaryngol Head Neck Surg 2021;147(07):674-676. Doi: 10.1001/jamaoto.2021.0869

11 Tseng PT, Chen TY, Sun YS, Chen YW, Chen JJ. The reversible tinnitus and cochleopathy followed first-dose AstraZeneca COVID-19 vaccination. QJM 2021;114(09):663-664. Doi: 10.1093/qjmed/hcab210

12 Mason MC, Liaqat A, Morrow J, Basso R, Gujrati Y. Bilateral Facial Nerve Palsy and COVID-19 Vaccination: Causation or Coincidence? Cureus 2021;13(08):e17602. Doi: 10.7759/cureus.17602

13 Sato K, Mano T, Niimi Y, Toda T, Iwata A, Iwatsubo T. Facial nerve palsy following the administration of COVID-19 mRNA vaccines: analysis of a self-reporting database. Int J Infect Dis 2021; 111:310-312. Doi: 10.1016/j.ijid.2021.08.071

14 Beukes E, Ulep AJ, Eubank T, Manchaiah V. The Impact of COVID19 and the Pandemic on Tinnitus: A Systematic Review. J Clin Med 2021;10(13):2763. Doi: 10.3390/jcm10132763

15 Oates CP, Turagam MK, Musikantow D, et al. Syncope and presyncope in patients with COVID-19. Pacing Clin Electrophysiol 2020;43(10):1139-1148. Doi: 10.1111/pace.14047

16 Jafari Z, Kolb BE, Mohajerani MH. Hearing Loss, Tinnitus, and Dizziness in COVID-19: A Systematic Review and Meta-Analysis. Can J Neurol Sci 2021;••:1-12 Epub ahead of print. Doi: 10.1017/ cjn.2021.63 